\title{
An unusual presentation of a rare neoplasm - Waldenstrom's macroglobulinemia
}

\author{
Samartha VA. ${ }^{1}$, Hegde S. ${ }^{2}$, Pai M.R. ${ }^{3}$, Ahmed Z. ${ }^{4}$ \\ ${ }^{1}$ Dr. Vinitha A. Samartha, Assistant Professor, ${ }^{2}$ Dr. Shreya Hegde, Assistant Professor, ${ }^{3}$ Dr. Muktha R Pai, Professor and \\ Head of Department, ${ }^{4}$ Dr. Zulfikar Ahmed, Associate Professor; all authors are affiliated with Department of Pathology, \\ A.J. Institute of Medical Sciences and Research Centre, Mangalore, Karnataka, India
}

Corresponding Author: Dr. Shreya Hegde, 403, Haribhakthi apartment, Pinto's lane, Mangalore, Karnataka, India. Email: drshreyahegde@gmail.com

\begin{abstract}
Waldenstrom's macroglobulinemia (WM) is a rare malignant lymphoproliferative disorder with an overall incidence of 2.5cases/ million/year. This is a case report of a 48-year-old woman who presented with an unusual, yet significant gastrointestinal involvement. Biopsy of the duodenum clinched the diagnosis of WM. Further bone marrow and serum electrophoresis confirmed the diagnosis. WM is an uncommon slow growing malignant monoclonal gammopathy which is chronic, indolent and predominantly involving the bone marrow and characterized by secretion of high levels of monoclonal immunoglobulin (IgM-hence called macroglobulinaemia), elevated serum viscosity and presence of lymphoplasmacytic infiltration of the bone marrow. This causes the most common non specific symptom of weakness and easy fatiguability. In some individuals, the IgM proteins clump together in the hands and feet, where the body temperature is cooler than at the centre of the body, hence being referred to as cryoglogubulins, their clumping causing a condition called cryoglobulinemia. Extramedullary involvement is rare and may affect central nervous system, articular and periarticular structures, lungs, kidneys, eyes, and gastrointestinal system.
\end{abstract}

Keywords: Lymphoplasmacytic Lymphoma, gastrointestinal, bone marrow.

\section{Introduction}

Waldenstrom's macroglobulinemia (WM) is a rare malignant lymphoproliferative disorder with an overall incidence of 2.5cases/ million/year [1]. Jan Gosta Waldenstrom, described the entity by identifying two patients with lymphadenopathy, oronasal bleeding, anemia, thrombocytopenia, elevated Erythrocyte sedimentation rate, serum hyperviscosity, as well as infiltration of the bone marrow by lymphoid cells [2].

According to the Revised European American Lymphoma (REAL) and World Health Organization (WHO), the bone marrow infiltrate was termed as lymphoplasmacytic lymphoma (LPL).

Subsequently, the consensus group at the Second International Workshop on WM in 2002 redefined a distinctive clinicopathologic entity characterized by bone marrow infiltration by lymphoplasmacytic lymphoma (LPL) cells and IgM monoclonal gammopathy [3]. Hence WM was re-designated as

Manuscript received: $20^{\text {th }}$ September 2019

Reviewed: $30^{\text {th }}$ September 2019

Author Corrected: $7^{\text {th }}$ October 2019

Accepted for Publication: $12^{\text {th }}$ October 2019
LPL/WM in REAL and WHO classification. Extramedullary infiltration of other organs by neoplastic cells is rare, with gastrointestinal involvement being even rare.

The incidence of WM is higher among whites (95\%) with an incidence as low as $5 \%$ in blacks [4]. The median age of presentation is between 60-70 years with a higher incidence in men [1].

Nonspecific symptoms, such as easy fatiguability and weakness are the usual symptoms. With the progression of the disease, specific symptoms such as cytopenias, peripheral neuropathies and abdominal pain become evident due to organ involvement [5].

Because of the late age of presentation of WM, half of the patients succumb to causes unrelated to WM. Unlike the usual symptoms, in this case, the presenting symptoms were abdominal pain, vomiting and diarrhea.

The medical literature studies reveal the rarity and low incidence of gastrointestinal involvement in WM. 


\section{Case Report}

\section{Case Report}

A 48-year-old female patient, hailing from South India presented with abdominal pain since 1 month, vomiting and loose stools since 4 days. Per abdomen examination revealed tenderness in the left hypochondriac region for 1 month. The Ultrasonography and Contrast enhanced computed tomography (CECT) showed massive splenomegaly measuring up to $19 \mathrm{cms}$ with abdominal lymphadenopathy which included porta hepatic and celiac lymph nodes with the largest one measuring $16 \mathrm{~mm}$. Peripheral smear was reported as microcytic hypochromic anemia with hemoglobin value of $7.2 \mathrm{~g} / \mathrm{dl}$. This was followed by endoscopy which revealed duodenitis. Histopathology of endoscopic biopsy showed clubbing and blunting of villi with increased lymphoplasmacytic infiltrate. Deposition of amorphous acellular eosinophilic material in the tips of villi, base of the mucosa raised the suspicion of WM (Figure 1,2). The amorphous deposits were PAS positive and Congo Red negative which ruled out amyloidosis. Hence the impression of WM was suggested.

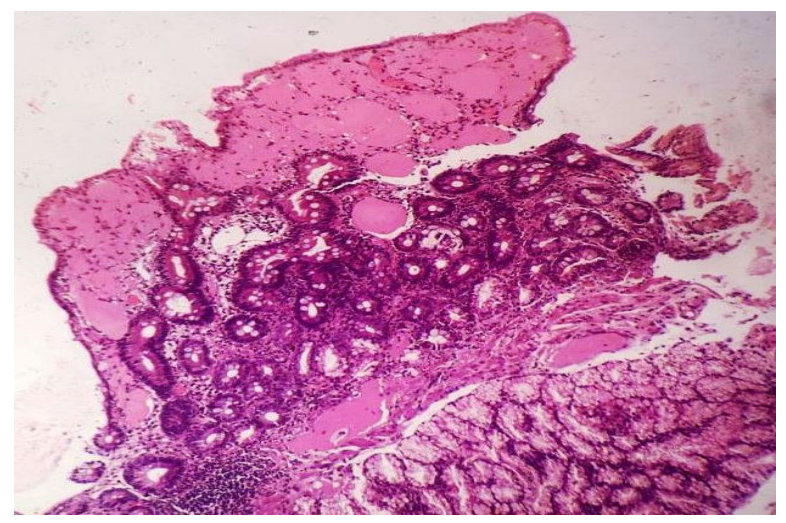

Figure 1: Acellular eosinophilic deposition in the tips of villi (H and E, x10).

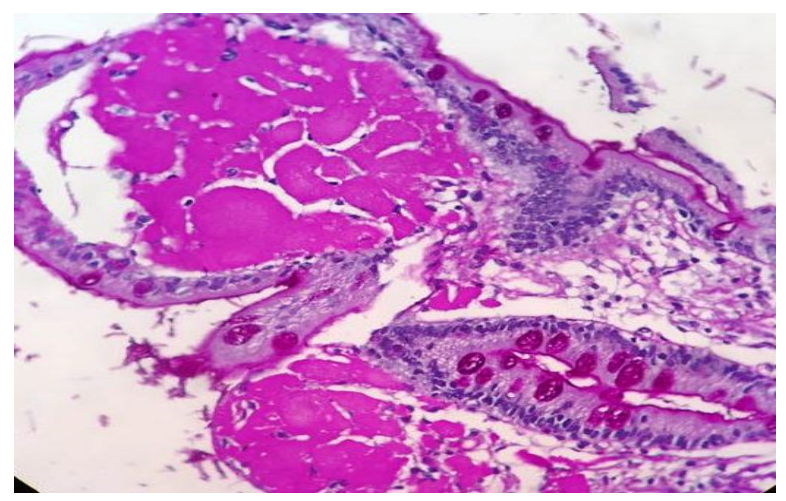

Figure 2: PAS positive deposits (PAS, x10).

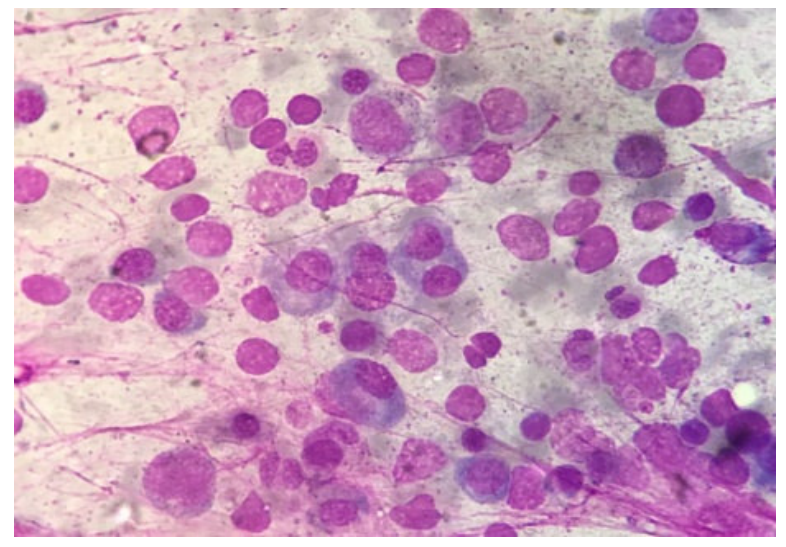

Figure 3: Bone marrow aspirate smear showing predominantly mature appearing lymphocytes and plasma cells (Leishman's stain, x10). 


\section{Case Report}

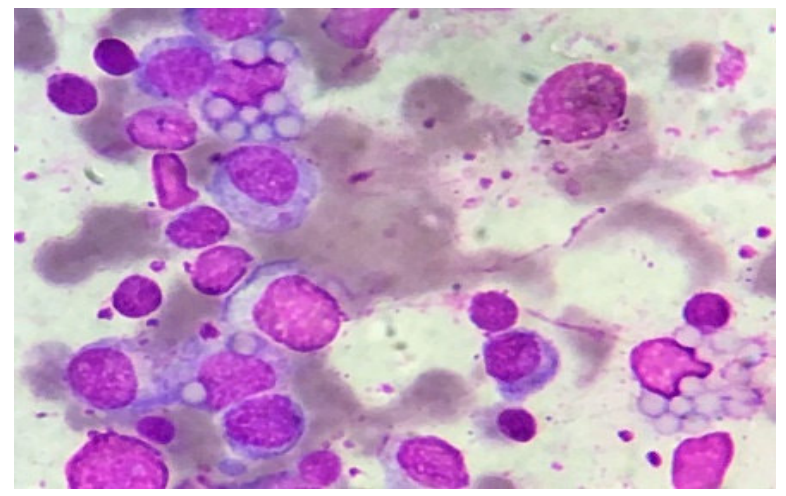

Figure 4: Bone marrow aspirate smear displaying Mott cells (Leishman's stain, x40).

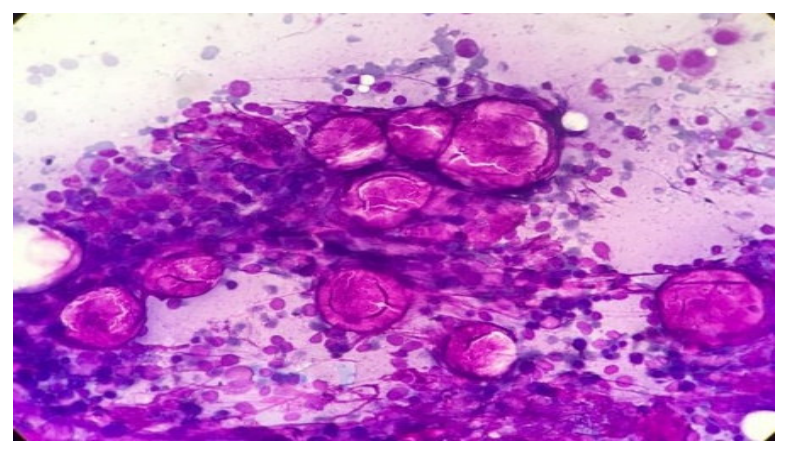

Figure 5: Acellular eosinophilic deposits in bone marrow aspirate smears (Leishma's stain, x10).

Bone marrow aspiration and biopsy showed 20\% plasma cells along with plasmacytoid lymphocytes, Mott cells and mast cells (Figure 3, 4, 5) Reticulin stain on bone marrow biopsy showed diffuse fibre network with scattered thick coarse fibres but no mature collagen (Grade 3$)$. The other susbstantiating positive findings were increased $\operatorname{IgM}(5570 \mathrm{mg} / \mathrm{dl})$, high Lambda $(2450 \mathrm{mg} / \mathrm{l})$ with protein electrophoresis showing " $\mathrm{M}$ " band positivity in two regions - Band $1(0.33 \%)$ in Beta region and Band 2(3.58\%) in Gamma region. Beta 2 microglobulin was significantly high (7013g/l). Immunofixation Qualitative Serum analysis done showed positivity for IgM and Lambda. Bone marrow features, in association with histopathological study, clinical and biochemical parameters support the diagnosis of WM.

\section{Discussion}

Waldenstrom Macroglobulinemia is a sporadic disease with the B- cell clone to be the cell of origin of neoplasm and is long debated [5]. The International Workshop on Waldenstrom's Macroglobulinemia defined WM as a rare small B cell neoplasm with any level of serum $\operatorname{IgM}$ and bone marrow infiltration by $\geq 10 \%$ of nucleated cells consisting of plasmacytoid lymphocytes and plasma cells.

This lymphoma is predominantly seen in the elderly, around 73 years of age group with a male predominance [6]. The clinical presentations of WM depend on two main factors, which include the effects due to elevated monoclonal Ig $\mathrm{M}$ paraprotein concentration and infiltration of organs by neoplastic cells [7]. Tumour infiltration to bone marrow leads to cytopenias and progressive anemias. The neoplastic cells can also infiltrate other organs, including, lymph nodes, liver and spleen presenting as organomegalies [4]. The larger size and increased concentration of the monoclonal protein leads to an increased vascular resistance and hyper viscosity. IgM may interact with coagulation factors or coat platelets and may cause abnormalities in bleeding and coagulation profiles.[4]

The high concentration of monoclonal Ig $\mathrm{M}$ above $4000 \mathrm{mg} / \mathrm{dl}$ leads to serum hyper viscosity which leads to the common presentation of headaches, visual disturbances, bleeding (epistaxis, bleeding gums and gastrointestinal bleeding) in WM [8]. Circulating IgM may undergo precipitation at cooler temperatures and may present as cryoglobulinemia [2]. However, the present case was unique due to the absence of any hyper viscosity symptoms though the $\operatorname{IgM}$ levels were $5570 \mathrm{mg} / \mathrm{dl}$. The non-specific frequent symptoms are easy fatiguablilty and weakness. Extramedullary WM, as evident in the present case, is defined as the presence of a clonal lymphoplasmacytic infiltrate in distant sites 


\section{Case Report}

from the bone marrow or adjacent soft tissue in a patient with underlying WM, excluding splenomegaly/ hepatomegaly /nodal involvement as well as circulating tumour cells [3]. Deposition of $\operatorname{IgM}$ in organs and tissues lead to specific symptoms [2]. Neurological complaints and visual disturbances due to $\operatorname{IgM}$ deposition is comparatively common than other organs, according to literature studies.

Involvement of central nervous system gives rise to a rare disorder known as Bing Neel Syndrome [9]. The gastrointestinal tract involvement is a rare occurrence which is evident in this case with symptoms of diarrhea, malabsorption and vomiting [10]. Few of the patients present with cough, dyspnea and chest pain due to cellular infiltration of the pulmonary parenchyma [7].

In a study conducted on 985 patients diagnosed as WM by Banwait $\mathrm{R}$ et al, from the Dana -Farber Cancer institute in Boston, 43 patients were identified with extramedullary involvement. The frequent extramedullary sites in this study were pulmonary, soft tissue, cerebrospinal fluid, renal and bone. The rare extramedullary sites of WM involvement in this study were breast, colon, small bowel, conjunctiva, gall bladder, prostate and skin [3].

The annual clinical update in WM categorized these patients based on the following prognostic factors which include age( $>65$ years $)$, hemoglobin values $(\leq 11.5 \mathrm{~g} / \mathrm{dl})$, platelet $\operatorname{count}(\leq 1,00,000$ cells $/$ cumm $)$, b2microglobulin $(>3000 \mathrm{~g} / \mathrm{l})$ and $\operatorname{IgM} \operatorname{levels}(>7000 \mathrm{mg} / \mathrm{dl})$.

Each positive prognostic factor was assigned one point and the risk score was the sum of points which was stratified as low ( 0 or 1 ) excluding age, intermediate (2 or age $>65$ years) and high $(>2)$ [8]. This case falls into the intermediate category with a score of 2 with low hemoglobin and a significantly high b2-microglobulin [11]. Waldenstrom's Macroglobulinemia is a diagnosis of exclusion with other entities to be considered [8].

The differential diagnosis to be considered are other B cell lymphomas with plasmacytic differentiation, particularly MGUS, marginal zone lymphomas, follicular lymphoma, multiple myeloma or even plasma cell variant of Castleman's disease [9].

These diagnoses may be differentiated by assessment of clinical status of patients along with several examinations and laboratory tests. Ancillary studies such as B cell antigen markers, cytogenetics and genetic studies may be done [11]. However, due to financial constraints and the relevant laboratory tests already done, antigen markers and the other ancillary studies were not done in this case. Recent medical literature studies have debated about evolution of WM to diffuse large B Cell lymphoma (DLBCL). However, none of the clinicopathologic features at the time of diagnosis of WM to predict the risk of progression to DLBCL have not been identified [4]

Recent studies have revealed MYD88L265P as the most commonly recurring mutation in patients with WM. This novel genetic study may help in differentiating from the other non-IgM LPL from B-cell disorders having same clinicopathologic features $[12,13]$.

\section{Conclusion}

Gastrointestinal involvement in WM is extremely rare. The clinical findings such as vomiting, diarrhea and abdominal pain due to deposition of monoclonal $\operatorname{IgM}$ in the lamina propria and/or submucosa of intestine associated with relevant laboratory findings such as immunoglobulin profile, serum electrophoresis, b-2 microglobulin values helped to clinch this rare diagnosis with an unusual presentation.

Awareness of likely association of WM with gastrointestinal manifestations will expeditate the diagnosis which will have a better prognostic impact on the patient.

\section{Source(s) of support: Nil \\ Presentation at a meeting: Nil \\ Conflicting Interest: Nil}

\section{References}

1. Gertz MA, Fonseca R, Rajkumar SV. Waldenstrom's Macroglobulinemia. Oncol. 2000;5:63-67. doi: 10.1634/ the oncologist. 5-1-63.

2. Coimbra S, Neves R, Lima M, Belo L, Santos SA. Waldenstrom's Macroglobulinemia - a review. Rev Assoc Mes Bras. 2014;60(5):49-49. doi: 10.1590/18069282.60.05.019.

3. Banwait R, Aljawai Y, Cappuccio $J$ et al. Extramedullary Waldenstrom Macroglobulinemia. Am J Hematol. 2015;90(2):100-104. doi: 10.1002/ajh.23880.

4.Vijay A, Gertz MA. Waldenstrom Macroglobulinemia. Blood. 2007; 109(12): 5096-5103. doi:10. 1182 / blood-2006-11-055012.

5.Charakidis M, RussellD J.Spontaneous splenic rupture in Waldenstrom's Macroglobulinemia: a case report. J Med Case Rep. 2010;4:300-304. doi:10.1186/ 1752-1947-4-300. 


\section{Case Report}

6. Foucar K. Procurement and indications for bone marrow examination. In: Foucar $\mathrm{K}$, Reichard $\mathrm{K}$, Czuchlewski D,eds. Bone Marrow Pathology. Vol 1. $3^{\text {rd }}$ ed. Chicago: American Society of Clinical Pathologists Press; 2010:56.

7. Treon SP, Merlini G. Lymphoplasmacytic Lymphoma /Waldenstrom's Macroglobulinemia. In:Armitage JO, Mauch PM, Harris NL, Coiffier B, Dalla Favera R, eds. Non Hodgkins Lymphomas. $2^{\text {nd }}$ ed. Philadelphia: Lippincott Williams and Wilkins; 2010:217-231.

8. Sathyanarayan V, Das U, Shankaranand BS, Gupta S, Anvekar NJ, Lakshmaiah KC. An unusual case of Waldenstrom's Macroglobulinemia presented with nasopharyngeal involvement. Cancer; 2013:7;362-364. doi: 10.3332/ecancer.2013.362.

9.Sohani AR, Rodig SJ, Harris NL. Lymphoplasmacytic lymphoma and Waldenstrom's Macroglobulinemia. In: Jaffe ES, Arber DA, Campo E, Harris NL, QuintanillaMartinez L(eds). Hemato-pathology. Philadelphia: Elsevier; 2017:285-298.

10. Gertz AM. Waldenstrom Macroglobulinemia:2017 update on diagnosis, risk stratification and management. Am J Hematol. 2017:92(2);209-215. doi:10.1002/ajh. 24557.

11. Owen RG, Treon ST, Al-Katib A, Fonseca R, Greipp PR, McMaster ML, et al. Clinicopathological Definition of Waldenstrom's Macroglobulinemia: consensus panel recommendations from the second recommendations from the second international workshop on Waldenstrom's Macroglobulinemia.Semin Oncol. 2003; 30 (2): 110-115. doi : 10.1053/sonc.2003. 50082.

12. Treon SP, Xu L, Yang G, Zhou Y, Liu X, Cao Y, et al. MYD88L265P Somatic Mutation in Waldenstrom's Macroglobulinemia. The N Engl J Med 2012;367(9): 826-833. doi : 10.1056/NEJMoa1200710.

13. Pratz KW, Dingli D, Smyrk TC, Lust JA. Intestinal Lymphangiectasia with protein losing enteropathy in Waldenstrom Macroglobulinemia.Medicine;2007;86(4): 210-214.doi:10.1097/MD.0b013e31812e5242

\section{How to cite this article?}

Samartha VA, Hegde S, Pai M.R, Ahmed Z. An unusual presentation of a rare neoplasm - Waldenstrom's macroglobulinemia. Trop J Path Micro 2019; 5(10):822-826.doi:10.17511/jopm.2019.i10.11. 